\title{
Effects of morin on the pharmacokinetics of etoposide in 7,12-dimethylbenz[a]anthracene-induced mammary tumors in female Sprague-Dawley rats
}

\author{
SI HYUNG YANG ${ }^{1}$, HYEON GYEOM CHOI ${ }^{2}$, SOO-JEONG LIM ${ }^{3}$, MYUNG GULL LEE ${ }^{4}$ and SO HEE KIM ${ }^{5}$ \\ ${ }^{1}$ College of Pharmacy and Research Institute of Pharmaceutical Sciences, Seoul National University, Seoul; \\ ${ }^{2}$ College of Dentistry and Research Institute of Oral Science, Gangneung-Wonju National University, Gangneung; \\ ${ }^{3}$ Department of Bioscience and Biotechnology, Sejong University, Seoul; ${ }^{4}$ College of Pharmacy, \\ The Catholic University of Korea, Bucheon; ${ }^{5}$ College of Pharmacy and Research Institute \\ of Pharmaceutical Science and Technology, Ajou University, Suwon, Republic of Korea
}

Received October 10, 2012; Accepted November 22, 2012

DOI: $10.3892 /$ or.2012.2201

\begin{abstract}
Etoposide, used for the treatment of breast cancer, is mainly metabolized via hepatic cytochrome P450 (CYP) $3 \mathrm{~A} 4$ in humans and is also a substrate for p-glycoprotein (P-gp). Morin is known to be able to modulate the activities of metabolic enzymes including CYPs and can act as a potent P-gp inhibitor. The purpose of this study was to investigate the effects of morin on the pharmacokinetics of etoposide in rats with 7,12-dimethylbenz[a]anthracene (DMBA)-induced mammary tumors. Etoposide was administered intravenously $(2 \mathrm{mg} / \mathrm{kg})$ and orally $(10 \mathrm{mg} / \mathrm{kg})$ in control and DMBA rats without (DMBA-WOM) and with (DMBA-WM) morin $(15 \mathrm{mg} / \mathrm{kg})$. Protein and mRNA expression of CYP3A and P-gp was analyzed, and the tissue distribution of etoposide was also measured. Both protein and mRNA expression of CYP3A and $\mathrm{P}-\mathrm{gp}$ was inhibited by morin in the liver, intestine and breast tumors of DMBA-WM rats. After both intravenous and oral administration of etoposide in DMBA-WM rats, the total area under the plasma concentration-time curve from time zero to infinity (AUC) of etoposide was significantly greater, and the time-averaged total body clearance (CL) of etoposide was significantly slower than those in control and DMBA-WOM rats. The amount of etoposide recovered from each tissue was significantly higher in DMBA-WM rats, especially in the breast tumor, liver and large intestine. No significant differences between control and DMBA-WOM rats were observed. Taken together, greater AUC and slower CL of etoposide in DMBA-WM rats could possibly be due to the inhibition of
\end{abstract}

Correspondence to: Professor So Hee Kim, College of Pharmacy and Research Institute of Pharmaceutical Science and Technology, Ajou University, Suwon 443-749, Republic of Korea

E-mail: shkim67@ajou.ac.kr

Key words: etoposide, morin, DMBA-induced mammary tumors, P-gp, CYP3A, pharmacokinetics hepatic CYP3A (intravenous) and mainly due to the inhibition of intestinal CYP3A and P-gp (oral) by morin.

\section{Introduction}

Etoposide, a DNA topoisomerase II inhibitor, is a semisynthetic glucosidic derivative of podophyllotoxin (1). Etoposide, one of the most active and useful antitumor agents, has been widely used for the treatment of a wide range of malignancies including relapsed or refractory breast and ovarian cancers (2). Etoposide is metabolized via the hepatic cytochrome P450 (CYP) to form O-demethylation based on rat liver microsomes (3) and human liver microsomes (4); CYP3A4 is a main CYP isoform involved in the 3'-demethylation of etoposide, and CYP1A2 and CYP2E1 are involved as the minor enzymatic components in this metabolic pathway based on human liver microsomes and nine recombinant human CYP isoforms (5). Moreover, etoposide is a substrate of P-glycoprotein (P-gp) based on the everted gut sacs prepared from the jejunum and ileum of rats (6) and its intestinal absorption is regulated by P-gp (6,7). P-gp was found to restrict the oral (re)uptake of etoposide and to mediate its intestinal excretion across the gut wall (8). Higher plasma concentrations of etoposide by cyclosporine, an inhibitor of CYP3A4 and P-gp, in patients (9) and rats (10) were reported. It has also been reported that protein expression of CYP1A1, CYP2E1 and CYP3A4 was significantly lower in breast cancer tissue when compared with morphologically adjacent normal tissue in humans (11), and hepatic mRNA expression of $P X R$ and its downstream targets, $C Y P 3 A 4$ and $A B C B 1$, was reduced in breast cancer patients (12). However, the hepatic protein expression of CYP3A and P-gp in breast tumor patients or mammary tumor-bearing animals has not been investigated, yet the amount of etoposide could be affected by protein expression of the CYP3A subfamily and P-gp in the liver and intestine.

Flavonoids are phytochemicals that are found in various fruits and vegetables at high quantities and plant-derived beverages such as tea and red wine (13). Among the flavonoids, morin (3,5,7,2',4'-pentahydroxyflavone) exhibits various biological and biochemical activities including antioxidation, 
anti-mutagenesis, anti-inflammation and cardioprotective activities (14-16). Previous studies have reported that morin modulates the activities of metabolic enzymes including CYPs (17). Moreover, it has been reported that morin is a fairly potent P-gp inhibitor (18). Therefore, morin appears to be a dual inhibitor against the CYP3A subfamily and P-gp. Recently, it has been reported that morin increased the bioavailability $(F)$ of etoposide (19), tamoxifen (20), nicardipine (21), methotrexate (22) and talinolol (23) in rats through the inhibition of P-gp. However, these studies were conducted using normal rats not mammary tumor-bearing rats. Studies using mammary tumor-bearing animal models will provide more data on the disease-related pharmacokinetic characteristics of absorption and metabolism of etoposide by morin.

Thus, in the present study, the effects of morin on the pharmacokinetics and tissue distribution of etoposide were evaluated using the environmental carcinogen, 7,12-dimethylbenz[a] anthracene (DMBA) to induce mammary tumors in rats (DMBA rats) as an animal model of human breast cancer. Tumors that developed in these rats closely mimic those of human breast cancer (24). Changes in protein and mRNA expression of CYP3A and P-gp were also evaluated.

\section{Materials and methods}

Materials. Etoposide injectable solution $(20 \mathrm{mg} / \mathrm{ml})$ was kindly donated by Korea United Pharmaceutical Company (Seoul, Korea). Podophyllotoxin [internal standard for high performance liquid chromatography (HPLC) analysis of etoposide], DMBA, dextran (MW 65,000), olive oil, primary monoclonal antibody for glyceraldehyde-3-phosphate dehydrogenase (GAPDH) and Kodak X-OMAT film were all purchased from Sigma-Aldrich Corp. (St. Louis, MO, USA). Polyclonal anti-rabbit CYP3A antibody was purchased from Detroit R\&D (Detroit, MI, USA) and monoclonal P-gp antibody was purchased from Calbiochem (EMD Biosciences Inc., San Diego, CA, USA). Horseradish peroxidase-conjugated goat anti-rabbit and anti-mouse secondary antibodies and enhanced chemiluminescence reagents were purchased from Bio-Rad Laboratories (Hercules, CA, USA) and Amersham Life Science Inc. (Piscataway, NJ, USA), respectively. Other chemicals were of reagent or HPLC grade.

Animals. The protocols for the animal studies were approved by the Animal Care and Use Committee of the Institute of Laboratory Animal Resources of Seoul National University (Seoul, Republic of Korea). Female Sprague-Dawley rats (ages 6-7 weeks and weighing 160-180 g) were purchased from Charles River Company Korea (Orient, Seoul, Republic of Korea). The procedures used for housing and handling of the rats were similar to those reported previously $(25,26)$.

Induction of mammary tumors in rats. DMBA (dissolved in olive oil) at a dose of $5 \mathrm{mg}$ (in $1 \mathrm{ml}$ ) per rat was administered orally using a gastric gavage tube once a week for 4 weeks as a previously reported method (27). This protocol not only results in palpable tumors as early as 3 weeks following the last administration of DMBA but also dramatically increases the number of tumors for each rat; more than the classic Huggins model (28). Morphological characteristics of the tumors induced by this protocol are identical to those of the Huggins model.

Preliminary study. The serum samples of control rats and DMBA rats $(n=5$, each group) were collected from the carotid artery for the measurement of total proteins, albumin, urea nitrogen, glutamate oxaloacetate transaminase (GOT), glutamate pyruvate transaminase (GPT) and creatinine (measured by Green Cross Reference Laboratory, Seoul, Republic of Korea). The whole liver, kidney and tumor (for mammary tumor rats) of each rat were excised, rinsed with $0.9 \% \mathrm{NaCl}$-injectable solution, blotted dry with tissue paper and weighed. Small portions of each organ were fixed in $10 \%$ neutral phosphatebuffered formalin and then processed for routine histological examination with hematoxylin and eosin staining.

RNA extraction and cDNA synthesis. Liver, intestine and breast tumor samples for protein and RNA isolation were obtained $30 \mathrm{~min}$ after oral administration of morin $(15 \mathrm{mg} / \mathrm{kg})$. Total RNA was isolated from tissue samples followed by column purification using the RNeasy Mini kit (Qiagen, Valencia, CA, USA) according to the manufacturer's protocols. RNA was eluted from the spin column using RNase-free $\mathrm{dH}_{2} \mathrm{O}$. cDNA was prepared from RNA samples using High Capacity cDNA Reverse Transcription kit (Applied Biosystems, Foster City, CA, USA) according to the manufacturer's instructions.

Quantitative real-time reverse transcription-polymerase chain reaction $(q R T-P C R)$. The $\mathrm{qRT}-\mathrm{PCR}$ reaction was prepared using Power SYBR Green qPCR Master Mix (Applied Biosystems), and qRT-PCR was performed using the StepOne Real-Time PCR system (Applied Biosystems). Each sample had a final volume of $15 \mu \mathrm{l}$ containing $~ 100 \mathrm{ng}$ of cDNA. The appropriate genes in the rat for human CYP3A4 and P-gp proteins were $C Y P 3 A 3$ and $A B C B 7$, respectively, which were the most homologous corresponding to the human genes. The oligonucleotide primers for $C Y P 3 A 3$ (83-bp PCR product) were: 5'-GCAAGAGAAAGGCAAACCTG-3' (forward) and 5'-CTCCAAATGATGTGCTGGTG-3' (reverse). The primers for $A B C B 7$ (177-bp PCR product) were: 5'-GGT GCCCTTACTGTTGGAGA-3' (forward) and 5'-AGATGCCA TCGCTTTGTCTT-3' (reverse). GAPDH was used to normalize the $C Y P 3 A 3$ and $A B C B 7 \mathrm{qRT}$-PCR results. Relative mRNA levels of $C Y P 3 A 3$ and $A B C B 7$ were assessed using the $2^{-\Delta \Delta C t}$ method.

Immunoblot analysis. The procedures used were similar to a previously reported method (29). Hepatic microsomes were resolved by sodium dodecyl sulfated-polyacrylamide gel electrophoresis (SDS-PAGE) on a $7.5 \%$ gel $(10 \mu \mathrm{g}$ protein per lane; $n=2$, each). Proteins were transferred to a nitrocellulose membrane (Pall Corp., Ann Arbor, MI, USA) and then blocked for $2 \mathrm{~h}$ in Tris-buffered saline containing $0.1 \%$ (v/v) Tween-20 (TBS-T). For immunodetection, blots were incubated overnight (IKA-Labortechnik, Staufen, Germany) at $4^{\circ} \mathrm{C}$ with CYP3A or P-gp antibodies (diluted 1:1,000 in TBS-T containing 5\% bovine serum albumin) followed by incubation for $2 \mathrm{~h}$ at room temperature with a secondary antibody conjugated to horseradish peroxidase (diluted 1:10,000 in TBS-T containing $5 \%$ milk powder). The protein expression of CYP3A and P-gp 
was detected by enhanced chemiluminescence on Kodak $\mathrm{X}$-OMAT film. GAPDH was used as a loading control.

Measurement of rat plasma protein binding of etoposide. Protein binding of etoposide to fresh rat plasma from the control and DMBA rats $(n=4$, each) was measured using equilibrium dialysis at an etoposide concentration of $2 \mu \mathrm{g} /$ $\mathrm{ml}(30,31)$. After a $24-\mathrm{h}$ incubation, two $100-\mu \mathrm{l}$ aliquots were removed from each compartment and stored at $-70^{\circ} \mathrm{C}$ (Revco ULT 1490 D-N-S; Western Mednics, Asheville, NC, USA) until being used for HPLC analysis of etoposide $(19,32)$.

Studies of intravenous and oral administration. The procedures used for the pretreatment of rats including the cannulation of the carotid artery (for blood sampling) and the jugular vein (for drug administration in the intravenous study) of each rat were conducted in a similar manner to previously reported methods $(26,33)$. The rats were not restrained in the present study.

Morin was dissolved in distilled water and orally administered $(15 \mathrm{mg} / \mathrm{kg}) 30 \mathrm{~min}$ prior to the intravenous administration of etoposide using a gastric gavage tube. Etoposide injectable solution (diluted in $0.9 \% \mathrm{NaCl}$-injectable solution) at a dose of $2 \mathrm{mg} / \mathrm{kg}$ (34-36) in $2 \mathrm{ml}$ was manually infused via the jugular vein over $1 \mathrm{~min}$ in the control $(\mathrm{n}=6)$, DMBA-WOM $(\mathrm{n}=7)$ and DMBA-WM rats $(\mathrm{n}=7)$. Blood samples $(\sim 0.22 \mathrm{ml}$, each) were collected via the carotid artery at 0 (control), 1 (end of the infusion), 5, 15, 30, 60, 90, 120, 180 and 240 min after the start of the infusion of etoposide. Each blood sample was centrifuged immediately, and $100 \mu \mathrm{l}$ of plasma sample was stored at $-70^{\circ} \mathrm{C}$ until being used for the HPLC analysis of etoposide $(19,32)$. At the end of the experiment $(24 \mathrm{~h})$, each metabolic cage was rinsed with $10 \mathrm{ml}$ of distilled water and the rinsings were combined with the 24-h urine sample. After measuring the exact volume of the combined urine sample, two 100- $\mu 1$ aliquots of the combined urine sample were stored at $-70^{\circ} \mathrm{C}$ until being used for the HPLC analysis of etoposide $(19,32)$. At the same time ( $24 \mathrm{~h})$, each rat was exsanguinated and sacrificed by cervical dislocation. Then, the abdomen was opened and the entire gastrointestinal tract (including its contents and feces) of each rat was removed, transferred into a beaker containing $100 \mathrm{ml}$ of methanol (to facilitate the extraction of etoposide) and cut into small pieces using scissors. After manual shaking and stirring with a glass rod for $1 \mathrm{~min}$, two $100 \mu \mathrm{l}$ portions of the supernatant were collected from each beaker and stored at $-70^{\circ} \mathrm{C}$ until being used for the HPLC analysis of etoposide $(19,32)$.

Etoposide (the same solution used in the intravenous study) at a dose of $10 \mathrm{mg} / \mathrm{kg}$ (34-36) in $5 \mathrm{ml}$ was administered orally using a gastric gavage tube to the control $(\mathrm{n}=6)$, DMBA-WOM $(\mathrm{n}=6)$ and DMBA-WM $(\mathrm{n}=5)$ rats. Blood samples were collected at $0,5,15,30,45,60,90,120,180,240,360$ and $480 \mathrm{~min}$ after the oral administration of etoposide. Other procedures for the oral study were similar to those for the intravenous study.

Tissue distribution of etoposide after its oral administration . Etoposide (the same solution used in the oral study) at a dose of $10 \mathrm{mg} / \mathrm{kg}$ was administered orally using a gastric gavage tube in control, DMBA-WOM and DMBA-WM rats $(n=3$; each). Small portion of liver, small intestine, large intestine and breast tumor (for DMBA rats) from each rat was quickly excised at $90 \mathrm{~min}$ after oral administration. Each tissue sample was rinsed with cold $0.9 \% \mathrm{NaCl}$-injectable solution, blotted dry with tissue paper and weighed. Each tissue was homogenized with 4 volumes of $0.9 \% \mathrm{NaCl}$-injectable solution in a tissue homogenizer (Ultra-Turrax T25, Janke and Kunkel, IKA-Labortechnik) and centrifuged. Two 100- $\mu 1$ aliquots of plasma or supernatant of each tissue homogenate were stored at $-70^{\circ} \mathrm{C}$ until being used for the HPLC analysis of etoposide $(19,32)$.

HPLC analysis of etoposide. Concentrations of etoposide in the above biological samples were determined by a slight modification of a reported HPLC method $(19,32)$. In brief, $20 \mu \mathrm{l}$ of methanol containing $20 \mu \mathrm{g} / \mathrm{ml}$ of podophyllotoxin (internal standard) was added to $100 \mu 1$ of a biological sample and extracted with $1 \mathrm{ml}$ of ethyl acetate. After vortex-mixing and centrifugation $(16,000 \mathrm{x} \mathrm{g}$ for $10 \mathrm{~min})$, the organic layer was transferred into a clean Eppendorf tube and evaporated (Dry Thermobath, Eyela, Tokyo, Japan) under a gentle stream of nitrogen gas at $50^{\circ} \mathrm{C}$. The residue was reconstituted in $100 \mu \mathrm{l}$ of the mobile phase and $50 \mu 1$ was injected directly onto a reversed-phase $\left(\mathrm{C}_{18}\right)$ HPLC column (Inertsil ODS-2; $150 \mathrm{~mm}$, 1.0x4.6 mm, i.d.; particle size, $5 \mu \mathrm{m}$; Metachem Technologies, Redondo Beach, CA, USA). The mobile phases, methanol:water at a ratio of 50:50 (v/v) for rat plasma and gastrointestinal tract samples and 45:55 (v/v) for the urine samples, were run at a flow-rate of $1.0 \mathrm{ml} / \mathrm{min}$, and the column eluent was monitored using an ultraviolet detector at $220 \mathrm{~nm}$ at room temperature. The retention times of etoposide and podophyllotoxin (internal standard) in rat plasma and gastrointestinal tract samples were $\sim 6$ and $12 \mathrm{~min}$, respectively, and the corresponding values in rat urine samples were $\sim 10$ and $21 \mathrm{~min}$, respectively. The quantitation limits of etoposide in rat plasma, urine and gastrointestinal tract samples were $0.05,0.5$ and $0.5 \mu \mathrm{g} / \mathrm{ml}$, respectively. The inter- and intra-day coefficients of variation were $<10.9,9.61$ and $13.2 \%$ in the concentration ranges of 0.05 $5,000,0.5-5,000$ and $0.5-5,000 \mu \mathrm{g} / \mathrm{ml}$ for plasma, urine and gastrointestinal tract samples, respectively.

Pharmacokinetic analysis. Standard methods (37) were used to calculate the following pharmacokinetic parameters using a non-compartmental analysis (WinNonlin 2.1; Pharsight Corp., Mountain View, CA, USA): the total area under the plasma concentration-time curve from time zero to infinity (AUC) (38), the time-averaged total body, renal and non-renal clearances (CL, $\mathrm{CL}_{\mathrm{R}}$ and $\mathrm{CL}_{\mathrm{NR}}$, respectively), the terminal half-life, the first moment of AUC (AUMC), the mean residence time (MRT), the apparent volume of distribution at steady state $\left(V_{s s}\right)$ and the extent of absolute oral bioavailability $(F)$. The peak plasma concentration $\left(C_{\max }\right)$ and time to reach $C_{\max }\left(T_{\max }\right)$ were obtained directly from the experimental data.

Statistical analysis. A P-value $<0.05$ was deemed to be statistically significant using a Duncan's multiple range test of the Statistical Package for the Social Sciences (SPSS Inc., Chicago, IL, USA) and the posteriori analysis of variance (ANOVA) among the three means for the unpaired data. All data are expressed as mean $\pm \mathrm{SD}$ apart from $T_{\max }$ which was expressed as median (range). 

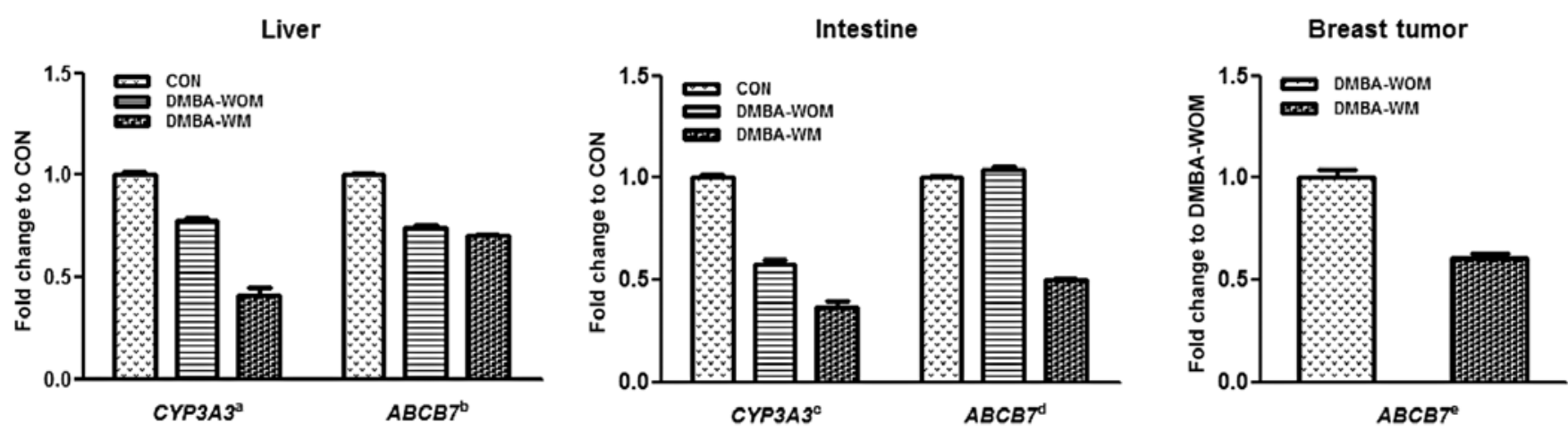

Figure 1. $C Y P 3 A 3$ and $A B C B 7 \mathrm{mRNA}$ expression in the liver, intestine and/or breast tumor in the control and DMBA rats without (DMBA-WOM) and with (DMBA-WM) morin $(15 \mathrm{mg} / \mathrm{kg})$. qRT-PCR was performed and the fold change was calculated using $2^{-\Delta \Delta C t}$ method compared to the control rats. GAPDH was used as a loading control. Vertical bars represent SD. ${ }^{a}$ The value for each group was significantly different $(\mathrm{P}<0.001)$. ${ }^{\mathrm{b}}$ The value for the control rats was significantly different $(\mathrm{P}<0.001)$ from the DMBA-WOM and DMBA-WM rats, while values for the DMBA-WOM and DMBA-WM rats were not significantly different. ${ }^{\circ}$ The value for the control rats was significantly different $(\mathrm{P}<0.001)$ from the DMBA-WOM and DMBA-WM rats, while values for the DMBA-WOM and DMBA-WM rats were significantly different $(\mathrm{P}<0.05)$. ${ }^{\mathrm{d}}$ The value for the DMBA-WM rats was significantly different $(\mathrm{P}<0.001)$ from the control and DMBA-WOM rats, while values for the control and DMBA-WOM rats were not significantly different. ${ }^{\circ}$ Values for the DMBA-WOM and DMBA-WM rats were significantly different $(\mathrm{P}<0.001)$. CYP3A3 was not detected in the breast tumors.

\section{Results}

Rat plasma protein binding of etoposide. Protein binding values of etoposide to fresh plasma from the control and DMBA rats were $73.0 \pm 6.20 \%$ and $60.6 \pm 5.56 \%$, respectively; the values were significantly different $(\mathrm{P}<0.05)$ between the two groups of rats.

qRT-PCR. The hepatic and intestinal mRNA levels of $C Y P 3 A 3$ and $A B C B 7$ were measured by qRT-PCR analysis using hepatic and intestinal RNA prepared from the control, DMBA-WOM and DMBA-WM rats. The $A B C B 7$ level was analyzed in breast tumors from the DMBA-WOM and DMBA-WM rats (Fig. 1). The expression of CYP3A3 in the DMBA-WOM and DMBA-WM rats was significantly decreased by 22.2 and $58.7 \%$ in the liver $(\mathrm{P}<0.001)$ and by 42.2 and $63.7 \%$ in the intestine $(\mathrm{P}<0.001)$, respectively, as compared to these values in the control. The expression of hepatic $A B C B 7$ was also significantly decreased $(\mathrm{P}<0.001)$ to 74.0 and $69.9 \%$ of the control in the DMBA-WOM and DMBA-WM rats. However, the expression of intestinal $A B C B 7$ was not changed in the DMBA-WOM rats compared to that in the control rats but was significantly decreased $(\mathrm{P}<0.001)$ in the DMBA-WM rats by 50.1 and $54.0 \%$ as compared to the control and DMBA-WOM rats, respectively. Similarly, the expression of $A B C B 7$ in the breast tumors was significantly decreased by $39.2 \%$ $(\mathrm{P}<0.001)$ in the DMBA-WM rats as compared to that in the DMBA-WOM rats, whereas CYP3A3 was not detected in breast tumors of both groups of rats. These results revealed that the mRNA expression of both $C Y P 3 A 3$ and $A B C B 7$ was inhibited by morin to a similar extent in the liver, intestine and breast tumors of the chemically induced mammary tumor-bearing rats apart from $A B C B 7$ in the intestine of DMBA-WOM rats.

Immunoblot analysis. The hepatic and intestinal protein levels for CYP3A and P-gp were determined by immunoblot analysis in all treated rats (Fig. 2). The hepatic CYP3A protein expression in DMBA-WM rats was significantly decreased $(\mathrm{P}<0.05)$ compared to the expression in the control and DMBA-WOM rats, whereas hepatic P-gp protein expression was not significantly different among all groups of rats. Intestinal CYP3A was significantly decreased in the DBMA-WOM $(\mathrm{P}<0.01)$ and DMBA-WM $(\mathrm{P}<0.001)$ rats compared to this value in the control rats; however, intestinal $\mathrm{P}$-gp protein expression increased by $25.0 \%$ in the DMBA-WOM rats but was significantly decreased by $26.1 \%(\mathrm{P}<0.05)$ in the DMBA-WM rats compared to the control rats and was significantly different $(\mathrm{P}<0.01)$ between the DMBA-WOM and DMBA-WM rats. The protein expression of CYP3A and P-gp was not detected in breast tumors of all groups.

Preliminary study. In DMBA rats, the serum levels of total proteins $(6.64 \pm 0.297$ vs. $7.46 \pm 0.550 \mathrm{~g} / \mathrm{dl}$ for DMBA and control rats, respectively) were significantly lower (by $11.0 \%$, $\mathrm{P}<0.05)$ than this level in the control rats, while the serum levels of GOT $(105 \pm 20.1$ vs. $68.8 \pm 13.8$ IU/1 for DMBA and control rats, respectively) were significantly higher (by $52.6 \%$, $\mathrm{P}<0.05)$ when compared with the control rats. In DMBA rats, the total protein level was in a similar range $(4.70-8.15 \mathrm{~g} / \mathrm{dl})$ as that reported but the GOT level was higher (45.7-80.8 IU/l) than values in rats reported previously (39). The serum levels of albumin, urea nitrogen, GPT, and creatinine clearance $\left(\mathrm{CL}_{\mathrm{CR}}\right)$ were not significantly different between the two groups of rats (data not shown). The above data suggest that the liver function seemed to be impaired in DMBA rats. This was supported by liver microscopy in the DMBA rats; mild chronic hepatitis, chronic portal inflammation with mild portal fibrosis and focal inflammation in granuloma were observed. However, there were no significant findings in the liver of control rats. No significant changes were observed in the kidneys of both groups of rats based on kidney microscopy. Moderately differentiated adenocarcinoma in the DMBA-induced mammary tumors was observed based on tumor microscopy.

Pharmacokinetics of etoposide after its intravenous administration. The mean arterial plasma concentration-time profiles for the intravenous administration of etoposide at a dose of $2 \mathrm{mg} / \mathrm{kg}$ in the control, DMBA-WOM and DMBA-WM rats 

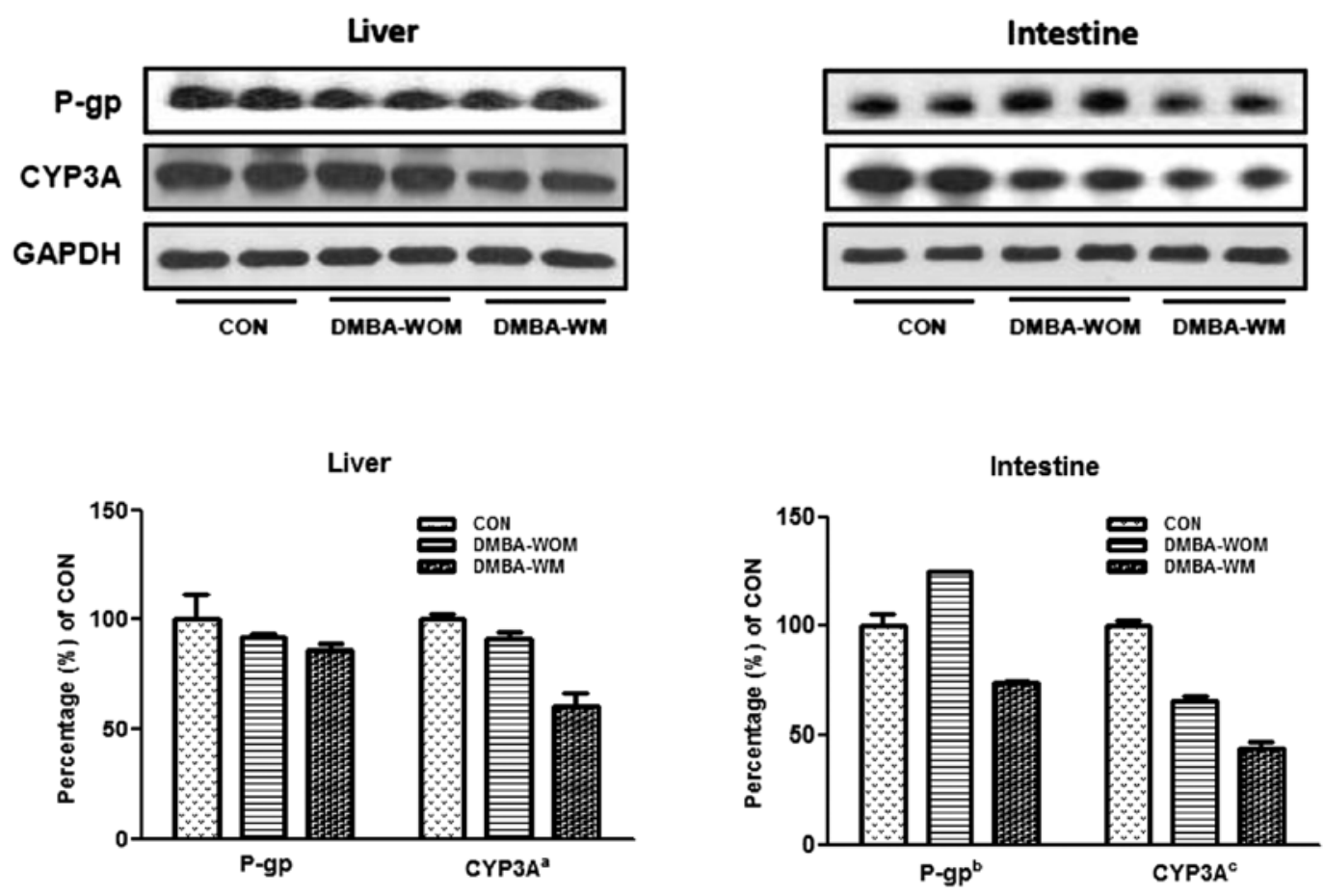

Figure 2. Hepatic and intestinal protein expression of CYP3A and P-glycoprotein (P-gp) in the control and DMBA rats without (DMBA-WOM) and with (DMBA-WM) morin $(15 \mathrm{mg} / \mathrm{kg}$ ). Immunoblot analysis was performed (top panels), the band density was quanititated (bottom panels) using Image $\mathrm{J}$ and the

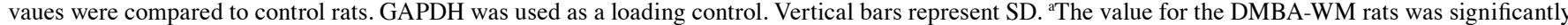
different $(\mathrm{P}<0.05)$ from the control and DMBA-WOM rats, while values for the control and DMBA-WOM rats were not significantly different. ${ }^{\circ}$ The value for the DMBA-WM rats was significantly different from control $(\mathrm{P}<0.05)$ and DMBA-WOM $(\mathrm{P}<0.01)$ rats, while values for the control and DMBA-WOM rats were not significantly different. ${ }^{\circ}$ The value for the control rats was significantly different $(\mathrm{P}<0.01)$ from the DMBA-WOM and DMBA-WM rats, while values for the DMBA-WOM and DMBA-WM rats were significantly different $(\mathrm{P}<0.05)$.

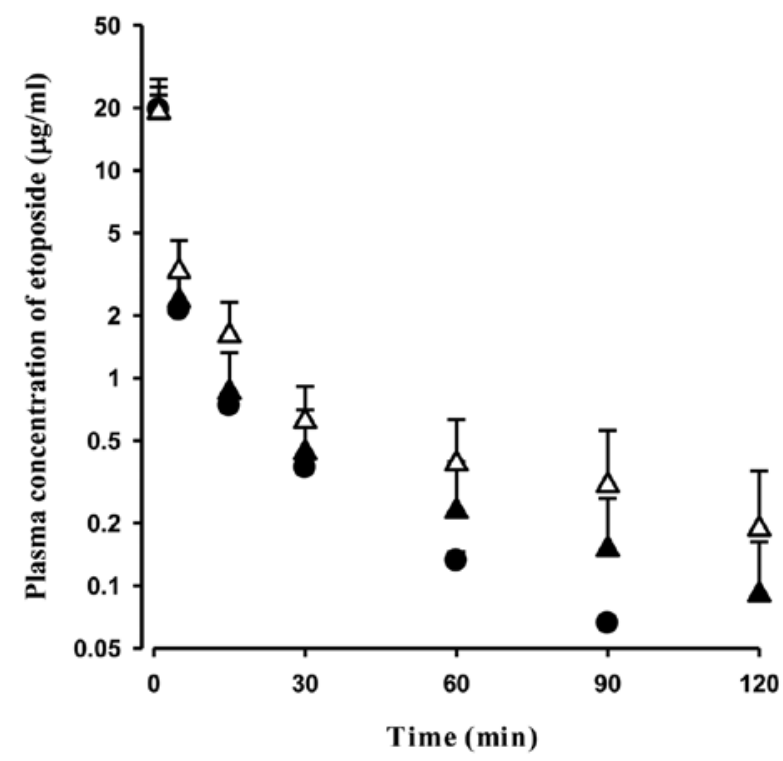

Figure 3. Mean arterial plasma concentration-time profiles of etoposide after 1-min intravenous infusion of etoposide $(2 \mathrm{mg} / \mathrm{kg})$ in control $(\bullet ; \mathrm{n}=6)$, DMBA-WOM $(\wedge ; n=7)$ and DMBA-WM $(\Delta ; \mathrm{n}=7)$ rats. Vertical bars represent SD.

are shown in Fig. 3. The relevant pharmacokinetic parameters are listed in Table I. In DMBA-WM rats, the AUC was significantly greater (by $64.8 \%, \mathrm{P}<0.05$ ) and considerably greater (by $49.9 \%, \mathrm{P}=0.103$ ), respectively, than the control and DMBA-WOM rats. Terminal half-life (by 157 and $54.4 \%$,

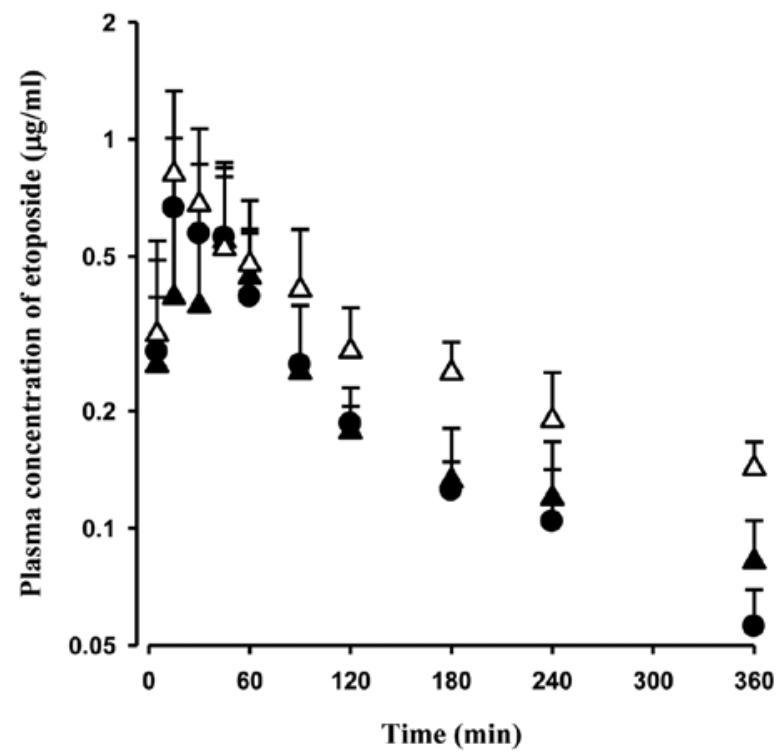

Figure 4. Mean arterial plasma concentration-time profiles of etoposide after oral administration of etoposide $(10 \mathrm{mg} / \mathrm{kg})$ in the control $(\bullet ; \mathrm{n}=6)$ and DMBA-WOM $(\Delta ; n=6)$ and DMBA-WM $(\triangle ; n=5)$ rats. Vertical bars represent $\mathrm{SD}$.

respectively) and MRT (by 194 and $75.8 \%$, respectively) were significantly longer when compared with the control and DMBA-WOM rats. $\mathrm{CL}$ and $\mathrm{CL}_{\mathrm{NR}}$ were significantly slower (by 34.1 and $36.1 \%$, respectively) in DMBA-WM rats than those of control rats, and $V_{s s}$ was significantly larger (by $76.8 \%$ ) 
Table I. Pharmacokinetic parameters of etoposide after its intravenous administration (2 $\mathrm{mg} / \mathrm{kg})$ in control and DMBA rats without (DMBA-WOM) and with (DMBA-WM) morin $(15 \mathrm{mg} / \mathrm{kg})$.

\begin{tabular}{lccc}
\hline Parameter & $\begin{array}{c}\text { Control } \\
(\mathrm{n}=6)\end{array}$ & $\begin{array}{c}\text { DMBA-WOM } \\
(\mathrm{n}=7)\end{array}$ & $\begin{array}{c}\text { DMBA-WM } \\
(\mathrm{n}=7)\end{array}$ \\
\hline Body weight $(\mathrm{g})$ & $294 \pm 13.9$ & $284 \pm 44.7$ & $272 \pm 20.6$ \\
AUC $(\mu \mathrm{g} \cdot \mathrm{min} / \mathrm{ml})^{\mathrm{a}}$ & $81.3 \pm 14.2$ & $89.4 \pm 39.6$ & $134 \pm 52.9$ \\
Terminal half-life $(\mathrm{min})^{\mathrm{b}}$ & $23.7 \pm 4.18$ & $39.5 \pm 4.83$ & $61.0 \pm 21.4$ \\
$\mathrm{MRT}(\mathrm{min})^{\mathrm{c}}$ & $15.8 \pm 3.44$ & $26.4 \pm 5.98$ & $46.4 \pm 20.2$ \\
$\mathrm{CL}(\mathrm{ml} / \mathrm{min} / \mathrm{kg})^{\mathrm{a}}$ & $25.2 \pm 4.07$ & $24.8 \pm 6.65$ & $16.6 \pm 4.79$ \\
$\mathrm{CL}$ & $(\mathrm{ml} / \mathrm{min} / \mathrm{kg})$ & $4.34 \pm 2.60$ & $2.71 \pm 1.33$ \\
$\mathrm{CL}$ & $2.56 \pm 1.27$ & $13.8 \pm 4.57$ \\
$V_{\mathrm{ss}}(\mathrm{ml} / \mathrm{kg} / \mathrm{min} / \mathrm{kg})^{\mathrm{a}}$ & $21.6 \pm 2.99$ & $631 \pm 141$ & $707 \pm 234$ \\
$A e_{0-24 \mathrm{~h}}(\%$ of i.v. dose $)$ & $400 \pm 112$ & $7.10 \pm 3.32$ & $6.88 \pm 3.53$ \\
$\mathrm{GI}_{24 \mathrm{~h}}(\%$ of i.v. dose $)$ & $5.52 \pm 1.40$ & $1.50 \pm 1.26$ & $1.40 \pm 0.811$ \\
\hline
\end{tabular}

Data are expressed as mean \pm standard deviation $(\mathrm{SD}) . A e_{0-24 \mathrm{~h}}$, percentage of the dose excreted in the 24-h urine; AUC, total area under the plasma concentration-time curve from time zero to infinity; $\mathrm{CL}$, time-averaged total body clearance; $\mathrm{CL}_{\mathrm{NR}}$, time-averaged non-renal clearance; $\mathrm{CL}_{\mathrm{R}}$, time-averaged renal clearance; $\mathrm{GI}_{24 \mathrm{~h}}$, percentage of the dose recovered from the gastrointestinal tract (including its contents and feces) at $24 \mathrm{~h}$; MRT, mean residence time; $V_{\mathrm{ss}}$, apparent volume of distribution at a steady state. ${ }^{a}$ The value for the DMBA-WM rats was significantly different $(\mathrm{P}<0.05)$ from the control rats. ${ }^{b}$ The value for each group was significantly different $(\mathrm{P}<0.05) .{ }^{\mathrm{c}}$ The value for the DMBA-WM rats was significantly different $(\mathrm{P}<0.05)$ from the control and DMBA-WOM rats. ${ }^{\mathrm{d}}$ The value for the control rats was significantly different $(\mathrm{P}<0.05)$ from the DMBA-WOM and DMBA-WM rats.

Table II. Pharmacokinetic parameters of etoposide after its oral administration $(10 \mathrm{mg} / \mathrm{kg})$ in control and DMBA rats without (DMBA-WOM) and with (DMBA-WM) morin $(15 \mathrm{mg} / \mathrm{kg})$.

\begin{tabular}{lccc}
\hline Parameter & $\begin{array}{c}\text { Control } \\
(\mathrm{n}=6)\end{array}$ & $\begin{array}{c}\text { DMBA-WOM } \\
(\mathrm{n}=6)\end{array}$ & $\begin{array}{c}\text { DMBA-WM } \\
(\mathrm{n}=5)\end{array}$ \\
\hline Body weight $(\mathrm{g})$ & $306 \pm 28.5$ & $318 \pm 36.9$ & $259 \pm 20.7$ \\
AUC $(\mu \mathrm{g} \cdot \mathrm{min} / \mathrm{ml})^{\mathrm{a}}$ & $82.0 \pm 23.0$ & $91.1 \pm 12.5$ & $148 \pm 28.5$ \\
Terminal half-life $(\mathrm{min})$ & $157 \pm 45.6$ & $208 \pm 73.3$ & $221 \pm 51.8$ \\
$C_{\max }(\mu \mathrm{g} / \mathrm{ml})$ & $0.777 \pm 0.243$ & $0.657 \pm 0.244$ & $0.895 \pm 0.492$ \\
$T_{\max }(\mathrm{min})^{\mathrm{b}}$ & $15.0(5.00-45.0)$ & $45.0(15.0-45.0)$ & $15.0(15.0-30.0)$ \\
$\mathrm{CL}_{\mathrm{R}}(\mathrm{ml} / \mathrm{min} / \mathrm{kg})$ & $2.75 \pm 1.43$ & $4.20 \pm 2.60$ & $1.69 \pm 1.42$ \\
$A e_{0-24 \mathrm{~h}}(\%$ of oral dose $)$ & $4.72 \pm 1.99$ & $7.64 \pm 4.45$ & $4.53 \pm 3.38$ \\
$\mathrm{GI}_{24 \mathrm{~h}}(\% \text { of oral dose })^{\mathrm{c}}$ & $23.6 \pm 8.67$ & $13.2 \pm 10.8$ & $11.2 \pm 5.10$ \\
$F(\%)$ & 20.2 & 20.4 & 22.1
\end{tabular}

Data are expressed as the mean \pm standard deviation (SD). $A e_{0-24 \mathrm{~h}}$, Percentage of the dose excreted in the 24-h urine; AUC, total area under the plasma concentration-time curve from time zero to infinity; $C_{\max }$, peak plasma concentration; $\mathrm{CL}_{\mathrm{R}}$, time-averaged renal clearance; $F$, extent of absolute oral bioavailability; $\mathrm{GI}_{24 \mathrm{~h}}$, percentage of the dose recovered from the gastrointestinal tract (including its contents and feces) at $24 \mathrm{~h} ; T_{\max }$, time to reach $C_{\max }$; ${ }^{\text {TT }}$ The value for DMBA-WM rats was significantly different $(\mathrm{P}<0.05)$ from the control and DMBA-WOM rats. ${ }^{\mathrm{b}}$ Median (ranges). ${ }^{\mathrm{c}}$ The value for the DMBA-WM rats was significantly different $(\mathrm{P}<0.05)$ from the control rats.

than that of the control rats. The pharmacokinetic values apart from terminal half-life and $V_{s s}$ were not significantly different between the control and DMBA-WOM rats.

Pharmacokinetics of etoposide after its oral administration. The mean arterial plasma concentration-time profiles for the oral administration of etoposide at a dose of $10 \mathrm{mg} / \mathrm{kg}$ in the control, DMBA-WOM and DMBA-WM rats are shown in
Fig. 4. The relevant pharmacokinetic parameters are listed in Table II. After the oral administration of etoposide, its absorption from the rat gastrointestinal tract was rapid; etoposide was detected in the plasma from the first blood sampling time point $(5 \mathrm{~min})$ for all rats studied. In DMBA-WM rats, the AUC was significantly greater (by 80.5 and $62.5 \%$, respectively) than AUC in the control and DMBA-WOM rats, and the percentage of the dose recovered from the gastrointestinal 


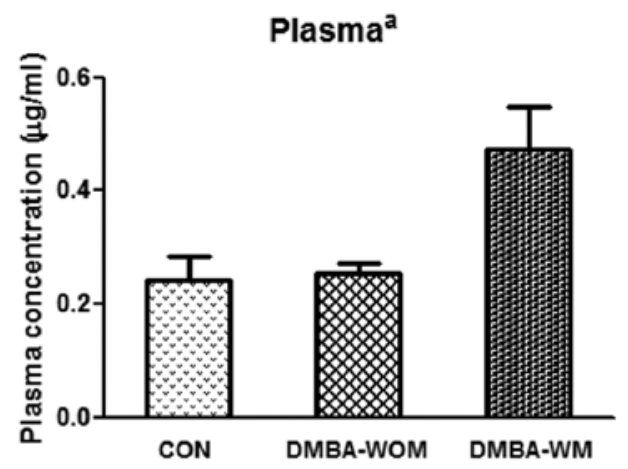

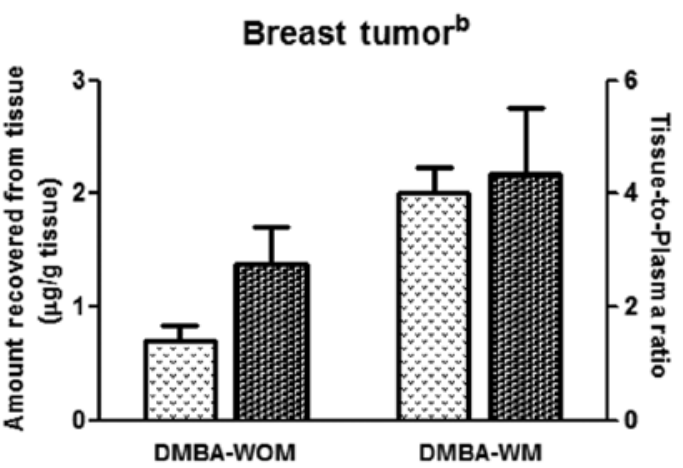

Small intestine

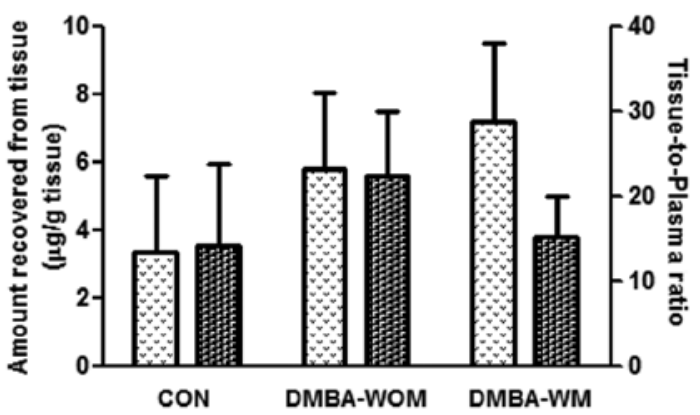

Liver ${ }^{\mathrm{a}}$

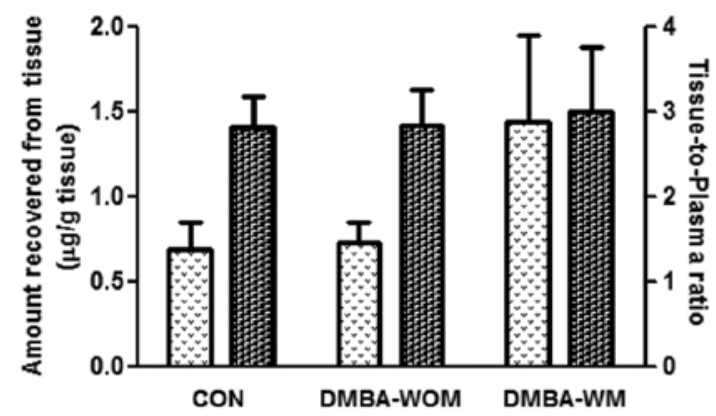

Large intestine ${ }^{c}$

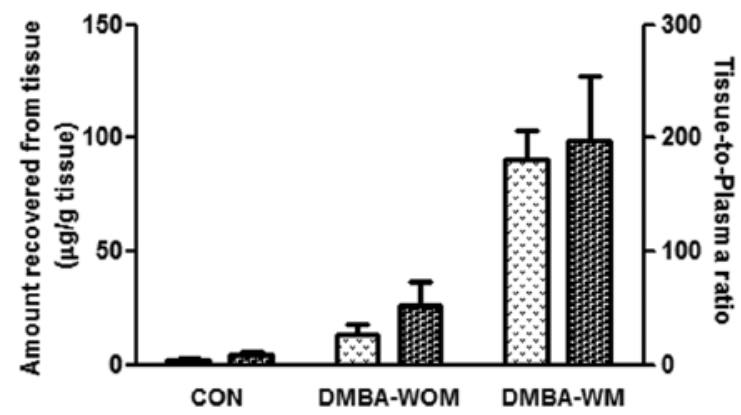

Figure 5. Plasma concentration $(\mu \mathrm{g} / \mathrm{ml})$ and amount ( $\mu \mathrm{g} / \mathrm{g}$ tissue) of etoposide recovered from each tissue (or organ) at 90 min after oral administration of etoposide $(10 \mathrm{mg} / \mathrm{kg})$ in control and DMBA rats without (DMBA-WOM) and with (DMBA-WM) morin $\left(15 \mathrm{mg} / \mathrm{kg}, \mathrm{n}=3\right.$, each). ${ }^{\mathrm{a}}$ The value for the DMBA-WM rats was significantly different $(\mathrm{P}<0.05)$ from the control and DMBA-WOM rats, while values for the control and DMBA-WOM rats were not significantly different. ${ }^{b}$ The value for the DMBA-WM rats was significantly different $(\mathrm{P}<0.01)$ from the DMBA-WOM rats. ${ }^{\circ}$ The value for the DMBA-WM rats was significantly different $(\mathrm{P}<0.001)$ from the control and DMBA-WOM rats, while values for the control and DMBA-WOM rats were significantly different $(\mathrm{P}<0.05)$. Statistical analysis was performed for the plasma concentration or amount recovered from tissue but not for the tissue-to-plasma ratios.

tract at $24 \mathrm{~h}\left(\mathrm{GI}_{24 \mathrm{~h}}\right)$ was significantly smaller (by $52.5 \%$ ) than this percentage in the control rats. The pharmacokinetic values were not significantly different between the control and DMBA-WOM rats.

Tissue distribution of etoposide after its oral administration. Tissue distribution of oral etoposide $(10 \mathrm{mg} / \mathrm{kg})$ in the liver, small intestine, large intestine and breast tumors (for mammary tumor rats) is shown in Fig. 5. Rat tissues had a good affinity to etoposide; the tissue-to-plasma ratios of etoposide at $90 \mathrm{~min}$ were greater than unity in all tissues studied. This could support the considerable $V_{s s}$ values of etoposide, in the range of 400-707 ml/kg (Table I). Generally, the amount of etoposide recovered from each tissue and/or the tissue-to-plasma ratios in rat studied were significantly higher in DMBA-WM rats, particularly in the breast tumors, liver and large intestine, compared to control rats (Fig. 5).

\section{Discussion}

It has been reported that etoposide is mainly metabolized in rat liver $(40,41)$. Thus, the $\mathrm{CL}_{\mathrm{NR}}$ values of etoposide listed in Table I may represent its hepatic metabolic clearances in rats. The contribution of the $\mathrm{CL}_{\mathrm{NR}}$ of etoposide to the $\mathrm{CL}$ was considerable; the values were greater than $83.1 \%$ in all groups of rats (Table I). Thus, the significantly greater AUC of intravenous etoposide in DMBA-WM rats could have been due to the significantly slower $\mathrm{CL}_{\mathrm{NR}}$ when compared to the control and DMBA-WOM rats (Table I). Etoposide is a drug with a low hepatic extraction ratio $(7.84 \%)$ in rats (36), thus its hepatic 
clearance depends on its hepatic intrinsic clearance and its free (unbound to plasma proteins) fraction in plasma (42).

Following the intravenous administration of etoposide in the control and DMBA-WOM rats, its AUC, CL and $\mathrm{CL}_{\mathrm{NR}}$ values were comparable (Table I). This suggests that DMBA did not considerably affect the hepatic metabolism of etoposide in rats, although in DMBA-WOM rats, the free fraction of etoposide in plasma was greater $(39.4 \%)$ than that in the control rats $(27.0 \%)$, and the mRNA level of hepatic CYP3A3 was significantly decreased when compared to the control rats (Fig. 1). The effect of free fraction on the hepatic clearance of etoposide could not be considerable since etoposide is a drug with a low hepatic extraction ratio; the free fraction of etoposide in plasma was already considerable $(27.0 \%)$ in the control rats and the protein expression of hepatic CYP3A subfamily was not significantly different in the DMBA-WOM rats compared to the control rats (Fig. 2). Therefore, in DMBA-WM rats, the greater $\mathrm{AUC}$ and slower $\mathrm{CL}_{\mathrm{NR}}$ of etoposide than those in control and DMBA-WOM rats could be due to inhibition of hepatic CYP3A by morin. This was supported by the protein and mRNA expression of CYP3A (Figs. 1 and 2). The hepatic protein and mRNA expression of CYP3A in DMBA-WM rats was significantly decreased when compared to the control and DMBA-WOM rats. Thus, the amount (concentration) of etoposide taken into the liver may be somewhat greater than the saturation level of hepatic metabolism of etoposide. The contribution of P-gp was not considerable since the protein expression of P-gp was not significantly different among the three groups of rats (Fig. 2).

Following the oral administration of etoposide in the control and DMBA-WOM rats, the AUCs were also comparable (Table II). This suggests that the effect of DMBA on the intestinal metabolism of etoposide was not considerable, even though the protein expression of CYP3A was decreased while the P-gp expression was increased in the DMBA-WOM rats compared to that in the control rats (Fig. 2). However, the AUC of etoposide in the DMBA-WM rats was significantly greater than the AUC noted in the control and DMBA-WOM rats. The protein expression of CYP3A and P-gp was significantly decreased in the DMBA-WM rats compared to the levels in the control and DMBA-WOM rats and this could be due to the inhibition of CYP3A and P-gp by morin (18) and thus contributed to the greater AUC of oral etoposide.

This finding was also supported by the increased tissue/ plasma ratio of etoposide in the DMBA-WM rats in the large intestine 90 min after oral administration of etoposide (Fig. 5). A similar result was reported that oral AUC of etoposide increased significantly (by $45.8 \%$ ) in rats via orally administered morin (19). Etoposide was reported to be a substrate for P-gp based on everted gut sacs prepared from rat jejunum and ileum (6) and its intestinal absorption was found to be regulated by $\mathrm{P}$-gp $(6,7)$. It has been reported that the transport of etoposide was significantly increased from the luminal site to the serosal site in the jejunum in the presence of P-gp inhibitor (43). A similar trend was also observed in the ileal sacs. This in vitro exsorption study also demonstrated that P-gp inhibitor reduced the efflux of etoposide to the luminal site in either the jejunum or ileum (43). Therefore, the significantly increased AUC of etoposide in the DMBA-WM group may be due to the increased absorption of etoposide from the gastrointestinal tract via inhibition of intestinal P-gp and decreased intestinal metabolism of etoposide via inhibition of intestinal CYP3A subfamily by morin. This was supported by the protein and mRNA expression of P-gp and CYP3A (Figs. 1 and 2). The intestinal protein and mRNA expression of P-gp in the DMBA-WM rats was significantly decreased compared to these values in the control rats. Thus, the amount (concentration) of etoposide absorbed through the intestine could be somewhat greater than the saturation level of intestinal metabolism of etoposide. The contribution of intestinal CYP3A subfamily was also considerable since the intestinal protein expression of CYP3A was significantly decreased in the DMBA-WM rats compared to levels in the control and DMBA-WOM rats (Fig. 2), which might reduce the intestinal first-pass metabolism of etoposide and increase the availability of etoposide.

In summary, in DMBA-WM rats, morin significantly increased the AUC of intravenous etoposide due to the inhibition of hepatic CYP3A. Morin also increased the AUC of oral etoposide. Greater AUC of oral etoposide was mainly due to the inhibition of intestinal P-gp and CYP3A subfamily by morin. These results are useful in predicting and designing clinical studies to investigate the interaction between etoposide and morin. In addition, if the present data obtained in rats is extrapolated to humans, the dosage regimen of etoposide used in the clinical situation should be modified to take account of the decreased metabolism and increased absorption of the drugs, particularly with chronic administration schedules. Further experiments in humans are required to confirm the above hypothesis.

\section{Acknowledgements}

This study was supported by Basic Science Research Program through the National Research Foundation of Korea (NRF) funded by the Ministry of Education, Science and Technology (2009-0066765).

\section{References}

1. Clark PI and Slevin ML: The clinical pharmacology of etoposide and teniposide. Clin Pharmacokinet 12: 223-252, 1987.

2. de Jong RS, Mulder NH, Dijksterhuis D and de Vries EG: Review of current clinical experience with prolonged (oral) etoposide in cancer treatment. Anticancer Res 15: 2319-2330, 1995.

3. van Maanen JM, de Vries J, Pappie D, van den Akker E, Lafleur VM, Retel J, van der Greef J and Pinedo HM: Cytochrome P-450-mediated O-demethylation: a route in the metabolic activation of etoposide (VP-16-213). Cancer Res 47: 4658-4662, 1987.

4. Relling MV, Nemec J, Schuetz EG, Schuetz JD, Gonzalez FJ and Korzekwa KR: O-demethylation of epipodophyllotoxins is catalyzed by human cytochrome P450 3A4. Mol Pharmacol 45: 352-358, 1994.

5. Kawashiro T, Yamashita K, Zhao XJ, Koyama E, Tani M, Chiba K and Ishizaki T: A study on the metabolism of etoposide and possible interactions with antitumor or supporting agents by human liver microsomes. J Pharmacol Exp Ther 286: 1294-1300, 1998.

6. Leu BL and Huang JD: Inhibition of intestinal P-glycoprotein and effects on etoposide absorption. Cancer Chemother Pharmacol 35: 432-436, 1995.

7. Makhey VD, Guo A, Norris DA, Hu P, Yan J and Sinko PJ: Characterization of the regional intestinal kinetics of drug efflux in rat and human intestine and in Caco-2 cells. Pharm Res 15: 1160-1167, 1998. 
8. Lagas JS, Fan L, Wagenaar E, Vlaming ML, van Tellingen O, Beijnen JH and Schinkel AH: P-glycoprotein (P-gp/Abcb1), Abcc2, and Abcc3 determine the pharmacokinetics of etoposide. Clin Cancer Res 16: 130-140, 2010.

9. Lum BL, Kaubisch S, Yahanda AM, Adler KM, Jew L, Ehsan MN, Brophy NA, Halsey J, Gosland MP and Sikic BI: Alteration of etoposide pharmacokinetics and pharmacodynamics by cyclosporine in a phase I trial to modulate multidrug resistance. J Clin Oncol 10: 1635-1642, 1992.

10. Carcel-Trullols J, Torres-Molina F, Araico A, Saadeddin A and Peris JE: Effect of cyclosporine A on the tissue distribution and pharmacokinetics of etoposide. Cancer Chemother Pharmacol 54: 153-160, 2004

11. El-Rayes BF, Ali S, Heilbrun LK, Lababidi S, Bouwman D, Visscher D and Philip PA: Cytochrome P450 and glutathione transferase expression in human breast cancer. Clin Cancer Res 9: 1705-1709, 2003.

12. Sandanaraj E, Lal S, Selvarajan V, Ooi LL, Wong ZW, Wong NS, Ang PC, Lee EJ and Chowbay B: PXR pharmacogenetics: association of haplotypes with hepatic CYP3A4 and ABCB1 messenger RNA expression and doxorubicin clearance in Asian breast cancer patients. Clin Cancer Res 14: 7116-7126, 2008.

13. Dixon RA and Steele CL: Flavonoids and isoflavonoids - a gold mine for metabolic engineering. Trends Plant Sci 4: 394-400, 1999.

14. Francis AR, Shetty TK and Bhattacharya RK: Modulating effect of plant flavonoids on the mutagenicity of N-methyl-N'-nitro-Nnitrosoguanidine. Carcinogenesis 10: 1953-1955, 1989.

15. Hanasaki Y, Ogawa S and Fukui S: The correlation between active oxygens scavenging and antioxidative effects of flavonoids. Free Radic Biol Med 16: 845-850, 1994.

16. Fang SH, Hou YC, Chang WC, Hsiu SL, Chao P-DL and Chiang BL: Morin sulfates/glucuronides exert anti-inflammatory activity on activated macrophages and decreased the incidence of septic shock. Life Sci 74: 743-756, 2003.

17. Hodek P, Trefil P and Stiborova M: Flavonoids - potent and versatile biologically active compounds interacting with cytochromes P450. Chem Biol Interact 139: 1-21, 2002.

18. Zhang S and Morris ME: Effects of the flavonoids biochanin A morin, phloretin, and silymarin on P-glycoprotein-mediated transport. J Pharmacol Exp Ther 304: 1258-1267, 2003.

19. Li X, Yun JK and Choi JS: Effects of morin on the pharmacokinetics of etoposide in rats. Biopharm Drug Dispos 28: 151-156, 2007.

20. Shin SC, Piao YJ and Choi JS: Effects of morin on the bioavailability of tamoxifen and its main metabolite, 4-hydroxytamoxifen, in rats. In Vivo 22: 391-396, 2008

21. Piao YJ and Choi JS: Effects of morin on the pharmacokinetics of nicardipine after oral and intravenous administration of nicardipine in rats. J Pharm Pharmacol 60: 625-629, 2008.

22. Hong SS, Jin MJ and Han HK: Enhanced systemic availability of methotrexate in the presence of morin in rats. Biopharm Drug Dispos 29: 189-193, 2008.

23. Pathak SM and Udupa N: Pre-clinical evidence of enhanced oral bioavailability of the P-glycoprotein substrate talinolol in combination with morin. Biopharm Drug Dispos 31: 202-214, 2010.

24. Russo J and Russo IH: Atlas and histologic classification of tumors of rat mammary gland. J Mammary Gland Biol Neoplasia 5: 187-200, 2000.

25. Kim YC, Lee I, Kim SG, Ko SH, Lee MG and Kim SH: Effects of glucose supplementation on the pharmacokinetics of intravenous chlorzoxazone in rats with water deprivation for 72 hours. Life Sci 79: 2179-2186, 2006.
26. Yang SH, Lee JH, Lee DY, Lee MG, Lyuk KC and Kim SH: Effects of morin on the pharmacokinetics of docetaxel in rats with 7,12-dimethylbenz[a]anthracene (DMBA)-induced mammary tumors. Arch Pharm Res 34: 1729-1734, 2011.

27. Fendl KC and Zimniski SJ: Role of tamoxifen in the induction of hormone-independent rat mammary tumors. Cancer Res 52: 235-237, 1992.

28. Huggins C, Grand LC and Brillantes FP: Mammary cancer induced by a single feeding of polymucular hydrocarbons, and its suppression. Nature 189: 204-207, 1961.

29. Lee DY, Jung YS, Kim YC, Kim SY and Lee MG: Faster clearance of omeprazole in mutant Nagase analbuminemic rats: possible roles of increased protein expression of hepatic CYP1A2 and lower plasma protein binding. Biopharm Drug Dispos 30: 107-116, 2009.

30. Øie S and Guentert TW: Comparison of equilibrium times in dialysis experiments using spiked plasma or spiked buffer. J Pharm Sci 71: 127-128, 1982.

31. Choi YH, Lee I and Lee MG: Effects of cysteine on metformin pharmacokinetics in rats with protein-calorie malnutrition: partial restoration of some parameters to control levels. J Pharm Pharmacol 60: 153-161, 2008.

32. Shirazi FH, Bahrami G, Stewart DJ, Tomiak E, Delorme F, Noel D and Goel R: A rapid reversed phase high performance liquid chromatographic method for determination of etoposide (VP-16) in human plasma. J Pharm Biomed Anal 25: 353-356, 2001.

33. Kim SH, Choi YM and Lee MG: Pharmacokinetics and pharmacodynamics of furosemide in protein-calorie malnutrition. $\mathrm{J}$ Pharmacokinet Biopharm 21: 1-17, 1993.

34. Piao YJ, Li X and Choi JS: Effects of verapamil on etoposide pharmacokinetics after intravenous and oral administration in rats. Eur J Drug Metab Pharmacokinet 33: 159-164, 2008.

35. Li X and Choi JS: Effects of quercetin on the pharmacokinetics of etoposide after oral or intravenous administration of etoposide in rats. Anticancer Res 29: 1411-1415, 2009.

36. Suh JH, Kang HE, Yoon IS, Yang SH, Lee HJ, Shim CK and Lee MG: Cysteine effects of cysteine on the pharmacokinetics of etoposide in protein-calorie malnutrition rats: increased gastrointestinal absorption by cysteine. Xenobiotica 41: 885-894, 2011.

37. Gibaldi M and Perrier D: Pharmacokinetics. 2nd edition. MarcelDekker, New York, 1982.

38. Chiou WL: Critical evaluation of the potential error in pharmacokinetic studies using the linear trapezoidal rule method for the calculation of the area under the plasma level-time curve. J Pharmacokinet Biopharm 6: 539-546, 1978.

39. Mitruka BM and Rawnsley HM: Clinical Biomedical and Hematological Reference Values in Normal Experimental Animals and Normal Humans. 2nd edition. Masson Publishing USA Inc., New York, pp161-162, 1981.

40. Hande K, Anthony L, Hamilton R, Bennett R, Sweetman B and Branch R: Identification of etoposide glucuronide as a major metabolite of etoposide in the rat and rabbit. Cancer Res 48: 1829-1834, 1988

41. Hande K, Bennett R, Hamilton R, Grote T and Branch R: Metabolism and excretion of etoposide in isolated, perfused rat liver models. Cancer Res 48: 5692-5695, 1988.

42. Wilkinson GR and Shand DG: A physiological approach to hepatic drug clearance. Clin Pharmacol Ther 18: 377-390, 1975.

43. Kan WM, Liu YT, Hsiao CL, Shieh CY, Kuo JH, Huang JD and Su SF: Effect of hydroxyzine on the transport of etoposide in rat small intestine. Anticancer Drugs 12: 267-273, 2001. 